\title{
Green Light in Phototherapy
}

\author{
C. VECCHI, ${ }^{(14)}$ G. P. DONZELLI, M. G. MIGLIORINI, AND G. SBRANA \\ Instituto di Puericultura, Università di Firenze, Italy [C.V., G.P.D.]; Istituto di Chimica Fisica, Università di Firenze, \\ Italy [M.G.M.]; and Centro di Studio sulla Chimica e la Struttura dei Composti Eterociclici del CNR, Firenze, Italy
}

[G.S.]

\begin{abstract}
Summary
Photodegradation of bilirubin in vivo has been investigated by using green fluorescent sources according to the suggestions obtained in a previous study in vitro. Two groups of 50 jaundiced low-birth-weight infants were exposed to fluorescent light in phototherapy units under similar irradiant conditions. One group was exposed for $24 \mathrm{~h}$ to standard green tubes, the other, to daylight lamps. Newborns of the two groups were similar for gestational age, birthweight, and initial bilirubin concentration. $A$ greater decrease in the serum concentration of bilirubin was found in subjects exposed to the green light when compared with infants exposed to daylight lamps.

The use of green light is strongly suggested instead of the white, blue, and special blue lamps, because of the real efficiency, power and range of wave lengths.
\end{abstract}

Various types of fluorescent light with different wavelengths have been used in the management of icterus of newborn infants since 1958, when Cremer et al. (4) observed that light is a potent agent in reducing serum bilirubin levels. Phototherapy is now a very common practice in neonatal units for the prevention and treatment of hyperbilirubinemia in premature infants because of its low risk factor compared with other treatments; however, the use of phototherapy is not without biologic effects and complications (3).

The goal of the neonatologist is to reach the best result with the least damage. One aspect of the question is to find the most effective light source for phototherapy because each fluorescent lamp (daylight, cool-light, blue, and special blue) has different spectral distribution and different peaks of maximal emission. Up until now, only wavelengths of $420-490 \mathrm{~nm}$ were considered to be effective in bilirubin photodegradation $(5,6,11)$. Wavelengths longer than $500 \mathrm{~nm}$ were generally discarded because they fall outside the electronic absorption band of bilirubin. Only Ostrow et al. (8) attributed some efficiency in vitro to the yellow-green light, although they confirmed the superiority of the blue-violet light in destroying bilirubin.

In our previous investigation in vitro (12) we reached different results and proved that wavelengths longer than $500 \mathrm{~nm}$ are still largely efficient. In this paper we report the results obtained by using green light in the management of hyperbilirubinemia in low-birth-weight infants.

\section{MATERIALS AND METHODS}

This work was performed on two groups of low-birth-weight newborns who developed hyperbilirubinemia within the fifth day of life.

Fifty infants, randomly assigned, were exposed in a standard phototherapy unit to commercial green fluorescent lamps. The same apparatus with standard daylight fluorescent lamps was used to irradiate 50 infants having similar initial bilirubin level, birthweight, and gestational age.

Each newborn was placed in incubators (Isolette, air shield
Mod. $\mathrm{GmbH}$ ) with its own ideal environmental conditions. The incubators were surrounded by a semicylindrical phototherapy unit equipped with eight fluorescent lamps positioned about 60 $\mathrm{cm}$ away from the mattress.

Green and white lights were emitted by standard F20T $12 \mathrm{G}$ and F20T12DA lamps (Sylvania, Germany) with a 20 watt energy output. The radiant flux, measured by a power meter (Mod. 210 , Coherent Radiation, Palo Alto, CA), was $3.14 \mathrm{~mW} / \mathrm{cm}^{2}$ in both cases. This value was found to be constant inside the phototherapy unit up to $40 \mathrm{~cm}$ from the plane.

The spectral distribution of the lamps employed in our experiment is illustrated in Figure 1.

Newborns were submitted to phototherapy with initial serum bilirubin concentration of $20.4-10.3 \mathrm{mg} / \mathrm{dl}$. The treatment was discontinued when, after $24 \mathrm{~h}$ of exposure, the bilirubin level fell below the criteria for therapy. The range in birth weight was $700-2550 \mathrm{~g}$ and 24-41 wk gestational age.

Some typical clinical features of low-weight infants were present in the subjects examined (hypoglycemia and hypocalcemia). No infants with maternal-fetal blood group incompatiblity, other hemolytic diseases, respiratory distress, or sepsis were included.

Serum bilirubin concentration was determined by a modified Malloy-Evelyn colorimetric method (7).

\section{RESULTS}

Table 1 summarizes the results of the clinical experiment performed on three different groups of infants selected according to their initial bilirubinemia.

Infants of each group were exposed, half to green and half to day-light fluorescent lamps (control group). Groups I, II and III include subjects having an initial bilirubin level of 20-16, 16-12, and $12-10 \mathrm{mg} / \mathrm{dl}$, respectively. The final value, is the value we obtained after $24 \mathrm{~h}$ of continuous exposure. At this time, the phototherapy was discontinued in most of the cases because the bilirubin concentration fell below the safety level and no significant rebound was observed during the next $24 \mathrm{~h}$.

As shown in the last two columns of Table 1, where the decrement of bilirubin concentration is reported in $\mathrm{mg} / \mathrm{dl}$ and in $\%$, all the subjects exposed to green light exhibit a decrease of bilirubin level greater than that in the "control group" $(P<0.001)$. The superiority of green light is clearly evident in all the groups investigated; however, a greater efficiency is encountered in the subjects included in groups I and III.

Forty-four infants belonging to groups I and II, who presented a lower rate of bilirubin degradation, required a longer exposure to the light $(48 \mathrm{~h})$. Twenty-two newborns were exposed to green fluorescent lamps and 22 to day-light lamps. The results listed in Table 2 show that the green light is still more effective for longtime exposures, with a $3.7 \%$ greater decrement of bilirubin level.

\section{DISCUSSION}

In order to check the possibility of using "safer" spectral regions in the therapy of neonatal hyperbilirubinemia, the photodegradation process has been recently investigated in vitro by using the 


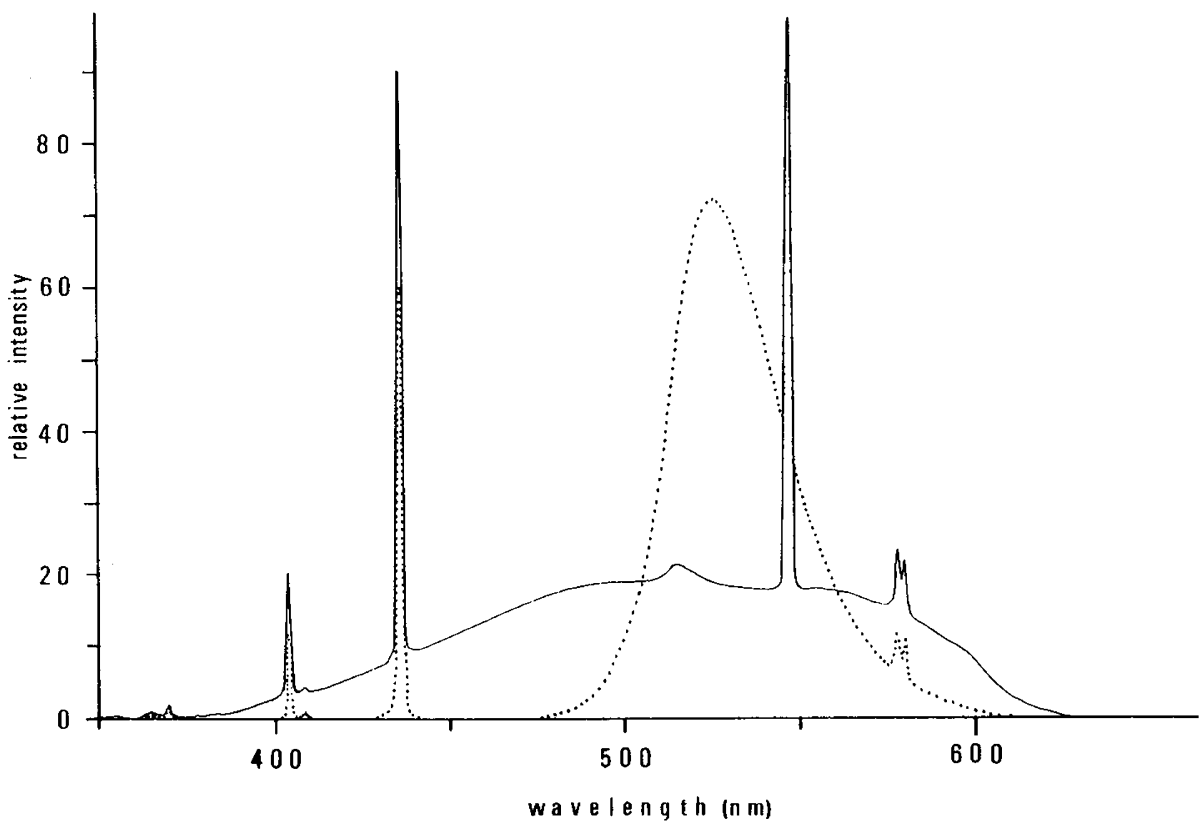

Fig. 1. Emission spectra of the green (----) and white (-) fluorescent tubes employed in phototherapy. Spectra were registered on a Cary 14 monochromator unit and a photomultiplier EMI 9558QB. Sharp bands are due to $\mathrm{Hg}$ emission.

Table 1. Serum bilirubin decrement in jaundiced newborns after $24 \mathrm{~h}$ exposure to green and white fluorescent tubes

\begin{tabular}{|c|c|c|c|c|c|c|c|c|c|c|c|c|}
\hline \multirow[b]{2}{*}{ Group } & \multirow{2}{*}{$\begin{array}{c}\text { No. of } \\
\text { subjects }\end{array}$} & \multirow[b]{2}{*}{ Lamps } & & & & & \multicolumn{4}{|c|}{ Bilirubin concentration (mg/dl) } & & \\
\hline & & & Range & Mean & Range & Mean & Range & Mean & Range & Mean & $\mathrm{mg} / \mathrm{dl}$ & $\%$ \\
\hline \multirow{2}{*}{ I } & 7 & $G^{1}$ & $34-36$ & 35 & $2180-2400$ & 2290 & $16.2-20.2$ & 17.0 & $11.2-18.7$ & 13.0 & 4.0 & 23.5 \\
\hline & 7 & $\mathrm{DA}^{2}$ & $34-38$ & 36 & $1500-2550$ & 2190 & $16.0-20.4$ & 17.8 & $13.0-17.7$ & 15.4 & 2.4 & 13.6 \\
\hline II & 29 & G & $24-40$ & 34 & $700-2450$ & 1910 & $12.2-15.6$ & 13.5 & $8.0-13.7$ & 10.9 & 2.6 & 19.3 \\
\hline III & 14 & DA & $31-39$ & 36 & $1740-2450$ & 2250 & $10.2-11.7$ & 11.0 & $7.7-10.0$ & 9.0 & 2.0 & 18.4 \\
\hline
\end{tabular}

${ }^{1} \mathrm{G}$, green (Sylvania F2OT12G).

${ }^{2} \mathrm{DA}$, daylight (Sylvania F2OT12DA).

Table 2. Serum bilirubin decrement in jaundiced newborns after $48 \mathrm{~h}$ exposure to green and white fluorescent tubes

\begin{tabular}{|c|c|c|c|c|c|c|c|c|c|c|c|}
\hline $\begin{array}{c}\text { No. of } \\
\text { subjects }\end{array}$ & Lamps & & & & & \multicolumn{4}{|c|}{ Bilirubin Concentration $(\mathrm{mg} / \mathrm{dl})$} & & \\
\hline 22 & $\mathrm{G}^{1}$ & $24-40$ & 33 & $700-2400$ & 2010 & $13.3-20.2$ & 15.0 & $6.4-17.1$ & 9.7 & 5.3 & 35.3 \\
\hline 22 & $\mathrm{DA}^{2}$ & $31-38$ & 34 & $1450-2550$ & 2000 & $12.2-20.4$ & 15.2 & $6.1-14.5$ & 10.4 & 4.8 & 31.6 \\
\hline
\end{tabular}

${ }^{1} \mathrm{G}$, green (Sylvania F2OT12G).

${ }^{2}$ DA, daylight (Sylvania F2OT12DA).

green line $(514.5 \mathrm{~nm})$ of an Argon ion laser in comparison with the blue $(488.0 \mathrm{~nm})$ and violet $(457.9 \mathrm{~nm})$ lines. These wavelengths have been found to be equally effective in obtaining up to a $30 \%$ drop in the bilirubin concentration (12).

Accordingly, we carried out a preliminary experiment in vivo to evaluate the possibility of exposing newborn infants to longer wavelengths, emitted by commercial fluorescent lamps. The results presented above, not only confirm the previous findings in vitro but even reveal a larger efficiency of green lamps with respect to the daylight lamps usually employed in the phototherapy units.

If we consider the spectral distribution of the sources (Fig. 1), we observe that the total energy output is the same for both the lamps (identical areas), but, owing to their different patterns, the amount of efficient light emitted by the green lamps is notably less.

From the clinical point of view, the importance of these results lies in the fact that a greater clinical effect is achieved with a lower energy light without the need of increasing the exposure time or the power density.

Presently, we have no direct data to compare the efficiency of green lamps with that of the special blue lamps recommended for phototherapy. From the published data (13), a 30\% decrement of 
bilirubin is achieved during 24-h exposure with special blue lamps at a power density of $2.9 \mathrm{~mW} / \mathrm{cm}^{2}$. With green lamps only $40 \%$ of the total emitted power falls within the absorption band of bilirubin; thus, the observed $23 \%$ bilirubin reduction during the $24-\mathrm{h}$ exposure corresponds to an effective power density of $1.2 \mathrm{~mW} /$ $\mathrm{cm}^{2}$.

The promising results obtained by our investigation suggest the use of green fluorescent lamps, instead of the other sources currently employed in phototherapy, on the basis of the following considerations: (1) no side reactions were observed in the infants; (2) most of the subjects reached a safety bilirubin level within the first $24 \mathrm{~h}$ of exposure; (3) the light flux produced in the phototherapy unit by eight fluorescent tubes is relatively low; (4) narrow-spectrum lamps were used emitting in the longer wavelengths regions; and (5) complete tolerance by nursery attendants. Even if the special blue lamps were more efficient, potential side effects, practically absent with green light, must be considered (2, $9,10)$.

With regard to the greater efficiency in vivo of wavelengths longer than $500 \mathrm{~nm}$, it is worth noting that the depth of penetration of visible light increases with increasing wavelengths (1). In fact, light scattering in tissues and the absorption coefficient of skin pigments (melanin, charotenoids, hemoglobin) decreases with increasing wavelengths. The optimum spectral range for producing an efficient photodegradation of bilirubin should result from a proper balance of light absorption by bilirubin and a proper penetration of the skin.

In conclusion, we wish to emphasize that our clinical experiment was performed using commercial fluorescent tubes. Even if the emission spectrum is remarkably narrow, studies are in progress on the use of suitable cut-off or special tubes to reduce the range of the emitted radiations.

\section{REFERENCES AND NOTES}

1. Anderson, R. R. and Parrish, J. A.: The optics of human skin. J. Invest. Dermatol., 77: 13 (1981)

2. Burki, H. M. and Lam, C. K.: Comparison of the lethal and mutagenic effects of gold and white fluorescent lights on cultured mammalian cell. Mut. Res., 54: 373 (1978).

3. Cohen, A. N. and Ostrow, J. D.: New concepts in phototherapy: photoisomerization of bilirubin IX $\alpha$ and potential toxic effects of light. Pediatrics, 65: 740 (1980).

4. Cremer, R. J., Perryman, P. W., and Richards, D. H.: Influence of light on hyperbilirubinemia of infants. Lancet, $1: 1094$ (1958).

5. Ente, G., Lanning, E. W., Cukor, P., and Klein, R. M.: Chemical variables and new lamps in phototherapy. Pediatr. Res., 6: 246 (1972).

6. Glauser, S. C., Lombard, S. A., Glauser, E. M., and Sisson, T. R. C.: Action spectrum for photodestruction of bilirubin. Proc. Soc. Exp. Biol. Med., 136: 518 (1971).

7. Mattenheimer, H.: Micromethods for the clinical and biochemical laboratory. p.47 (Scientific Publishers, Inc., Ann. Arbor 1970).

8. Ostrow, J. D. and Branham, R. V.: Photodecomposition of bilirubin and biliverdin in vitro. Gastroenterology, 58: 15 (1970).

9. Parshad, R., Ganit, R., Sanford, K. K., Jones, G. M., and Camalier, R. F.: Lightinduced chromatid damage in human skin fibroblasts in culture in relation to their neoplastic potential. Int. J. Cancer, 28: 335 (1981).

10. Parshad, R., Sanford, K. K., Taylor, W. G., Tarone, R. E., Jones, G. M., and Baeck, A. E.: Effect of the intensity and wavelength of fluorescent light on chromosome damage in cultured mouse cells. Photochem. Photobiol., 29: 971 (1979).

11. Raethel, H. A.: Wavelengths of light producing photodecomposition of bilirubin in serum from a neonate with hyperbilirubinemia. J. Pediatr. 87: 110 (1975).

12. Sbrana, G., Migliorini, M. G., Vecchi, C., and Donzelli, G. P.: Laser photolysis of bilirubin. Pediatr. Res., 15: 1517 (1981).

13. Sisson, T. R. C., Kedall, N., Shaw, E., and Kechavarz-Oliai, L.: Phototherapy of jaundice in the newborn infant. Effect of varyous light intensities. J. Pediatr., 81: 35 (1972).

14. Requests for reprints should be addressed to: Dr. C. Vecchi, Istituto di Puericultura, Ospedale Meyer via L. Giordano $13=50132$ Firenze, Italy.

15. This work was supported by the Italian Consiglio Nazionale delle Ricerche.

16. Received for publication February 9, 1982.

17. Accepted for publication September 17, 1982. 